\title{
Fatores associados à ocorrência de formas imaturas de Aedes aegypti na Ilha do Governador, Rio de Janeiro, Brasil
}

\author{
Factors associated to the ocurrence of immature forms of Aedes aegypti \\ in the Ilha do Governador, Rio de Janeiro, Brazil
}

\author{
Reinaldo Souza-Santos
}

\begin{abstract}
Resumo Aedes aegypti é o vetor urbano da dengue, doença que pode resultar em epidemias. Estudos ecológicos tornam-se importantes uma vez que populações do vetor de diferentes áreas podem diferir quanto a características bio-ecológicas, relevantes para orientar ações de controle. Este trabalho objetiva identificar e analisar fatores associados à ocorrência de formas imaturas de A. aegypti na llha do Governador, Rio de Janeiro, a partir dos dados da Fundação Nacional de Saúde (FNS). Os resultados mostram que 58,04\% do total de criadouros inspecionados foram constituídos por suportes para vasos com plantas, vasilhames de plástico ou vidro abandonados no peridomicílio. Maiores percentuais de criadouros positivos foram observados para pneus $(1,41 \%)$, tanques, poços e cisternas (0,93\%), e barris, tonéis e tinas (0,64\%). Maiores proporções de criadouros positivos durante o verão foram as dos grandes reservatórios de água e a dos criadouros provenientes do lixo doméstico. No inverno, verificamos maior valor para os pequenos reservatórios de água para uso doméstico. As maiores proporções de criadouros positivos foram observadas após três meses sem atividades da FNS. A análise fatorial mostrou que o principal fator determinante da ocorrência de fases imaturas de A. aegypti é aquele que leva em consideração os fatores meteorológicos. A eliminação e tratamento de criadouros pelos agentes da FNS apresentaram-se como menos importantes. Tais fatos apontam a necessidade de controle contínuo, indicando menor atenção da FNS, durante o inverno, em relação aos pequenos reservatórios, que podem manter formas imaturas de A. aegypti.
\end{abstract}

Palavras-chaves: Aedes aegypti. Culicidae. Vetores. Ecologia. Controle de Vetores.

\begin{abstract}
Aedes aegypti is the vector of dengue, a disease that can result in epidemics. Ecological studies are important because different geographical populations of the vector may differ in their bioecological characteristics, which can be helpful in guiding control actions. The objective of this study was to identify and to analyze some factors associated with the occurrence of immature forms of A. aegypti on Ilha do Governador, Rio de Janeiro, using data from the National Health Foundation (FNS). The results showed that $58.04 \%$ of all the containers examined were supports for plant pots, and plastic or glass cans discarded in the yard. The highest percentages of positive breeding sites were observed in tires (1.41\%), wells and cisterns (0.93\%), and barrels and large metal cans $(0.64 \%)$. In the summer, the proportion of positivity was higher for big containers used for water storage and for containers discarded in the yard. In the winter the proportion was higher for small containers used for water storage. The highest rates of positive containers were observed after three months without FNS activities. Our results show the necessity to continue the control, and suggest that less attention was paid to small containers during the winter by FNS. Factorial analysis showed that the determinant factor for the ocurrence of immature forms of A. aegypti is represented by environmental factors, while elimination and treatment of breeding sites by FNS play a less important role, a fact possiblly causing the maintenance of immature forms of A. aegypti.
\end{abstract}

Key-words: Aedes aegypti. Culicidae. Vectors. Ecology. Vector Control.

Departamento de Endemias Samuel Pessoa da Escola Nacional de Saúde Pública da Fundação Oswaldo Cruz.

Endereço para correspondência: Dr. Reinaldo Souza-Santos. Departamento de Endemias Samuel Pessoa/Esnp/Fiocruz. R. Leopoldo Bulhões 1480, 21041-210 Rio de Janeiro, RJ Brasil.

E-mail: rssantos@ensp.fiocruz.br

Recebido para publicação em 2/7/98. 
Aedes aegyptié o vetor da dengue, arbovirose com grande potencial de disseminação e que pode resultar em epidemias explosivas 1621. Este mosquito possui hábitat domiciliar e peridomiciliar, preferindo criadouros artificiais, tanto aqueles a céu aberto e preenchidos por água de chuvas, como aqueles utilizados para armazenar água para uso doméstico. Nestes criadouros pode haver proliferação de larvas e pupas de $A$. aegypti com a condição de que a água armazenada seja translúcida, acumulada em recipientes situados em locais sombreados e, preferencialmente, de fundo ou paredes escuras 222 . Essas também têm sido observadas em água acumulada entre as folhas de bromélias, ocos de árvores, escavações em rocha e bambu. Tais achados, no entanto, são raros em comparação com os chamados criadouros preferenciais, mencionados anteriormente 220. Esse mosquito é facilmente encontrado em locais de maior densidade populacional e, mais raramente, em ambientes semi-silvestres2 18.

A distribuição do $A$. aegypti no Brasil, com base nos dados da Fundação Nacional de Saúde (FNS), evidencia um aumento rápido no número de municípios infestados. Em 1980, 12 municípios; em 1986, 258; e em meados de 1995, 1251 municípios 19. Em 1976 verificou-se novo registro desta espécie no Rio de Janeiro, após um período de 31 anos sem ocorrência na cidade ${ }^{19}$.

Diversos estudos sobre ecologia e controle de A. aegypti, além da descrição de criadouros, têm sido desenvolvidos em vários países1 49141823. A importância dos estudos ecológicos recai, por exemplo, na constatação de que populações de $A$. aegypti, de diferentes áreas geográficas, podem diferir quanto a importantes características bioecológicas de relevância para orientar as ações de controle16 18.

Desse modo, torna-se necessária uma análise mais aprofundada da ecologia desta espécie no município do Rio de Janeiro, contribuindo assim para a adoção de medidas de controle mais eficazes. O objetivo deste trabalho é identificar e analisar fatores ambientais determinantes da ocorrência de formas imaturas de Aedes aegypti em um bairro do Rio de Janeiro a partir da investigação de dados coletados pela FNS por meio de visitas domiciliares, como parte do programa que visa ao controle dessa espécie.

\section{MATERIAL E MÉTODOS}

A área do estudo compreende o bairro do Galeão, localizado na Ilha do Governador, Rio de Janeiro. Este bairro possui $20,28 \mathrm{~km}^{2}$, que corresponde a $48,03 \%$ da área total da referida IIha. Nele se encontra, além do Aeroporto Internacional do Rio de Janeiro, áreas urbanizadas, favelas e áreas de vegetação. $\mathrm{O}$ número de habitantes em 1991 era de 17.562, com densidade bruta habitante/ha de 8,7. Do total de 4.354 domicílios, 92,8\% possuem canalização interna de água, 91,4\% estão ligados à rede geral de abastecimento de água, 96\% possuem canalização interna de esgoto, $75,7 \%$ estão conectado a rede geral de esgoto e $76,7 \%$ possuem lixo coletado diretamente 7 . A temperatura média é de $26,7^{\circ} \mathrm{C}$, máxima, e $20,4^{\circ} \mathrm{C}$, mínima, e a pluviosidade média anual é de $1.107 \mathrm{~mm}$, com freqüência média de 124 dias de chuva por ano 7 .

O período de estudo foi de junho de 1992 a julho de 1994. Para a análise foram utilizados: a) dados meteorológicos, temperatura -máxima e mínima-, pressão e umidade relativa do ar, fornecidos pelo Serviço Regional de Proteção ao Vôo do Rio de Janeiro, Ministério da Aeronáutica; b) informações obtidas a partir de visitas domiciliares efetuadas pelos funcionários da FNS que reportam, por semana de trabalho, a quantidade e os tipos de criadouros identificados, quantidade de criadouros eliminados e tratados, quantidade de larvicida (temefós) utilizado, tipo e quantidade de criadouros inspecionados, positivos ou não para larva e/ou pupa de A. aegypti. Os criadouros denominados eliminados são aqueles de que se retirou a água de seu interior e que foram colocados em outra posição, que impossibilite novo acúmulo de água. Já os tratados são criadouros onde foram utilizados larvicida. Os dados pluviométricos não foram analisados, pois eram oriundos de estações meteorológicas distantes do bairro do Galeão. Assim, utilizaram-se os dados sobre a umidade relativa do ar como indicador aproximado de pluviosidade.

As atividades da FNS são efetuadas em ciclos que têm a duração média de 3 meses cada um. Ao término de um ciclo em um setor do bairro, os funcionários encaminham-se para outro, onde reiniciam um novo ciclo. Após a cobertura de todos os setores designados, os funcionários retornam ao primeiro setor inspecionado. Assim, apesar de os dados não serem contínuos durante um ano, para um mesmo setor, a base de dados da FNS dispõe de informações relativas a seis ciclos de levantamentos. Estes são referentes aos 
seguintes períodos: $1^{0}$ ciclo - de 15/06/92 a 16/09/92; 2ํ ciclo - de 05/10/92 a 17/02/93; 3은 ciclo - 24/02/93 a 11/06/93; 4 ciclo - 21/06/93 a 20/08/93; 5o ciclo - 29/11/93 a 07/02/94; 6 ciclo - 06/04/94 a 28/07/94. Nos formulários da FNS os criadouros estão classificados em: árvores e plantas; barris, tonéis e tinas; calhas; caixas d'água; depósitos artificiais; depósitos de barro; pneus; tanques de concreto; cacimbas, poços e cisternas; e outros depósitos.

Segundo a rotina da FNS, as observações referentes aos encontros de larvas e pupas nos diversos tipos de criadouros são registradas separadamente. Contudo, para os fins deste estudo, os encontros de larvas e pupas foram agrupados em uma única variável, uma vez que estes estágios de desenvolvimento do mosquito ocorrem em um mesmo criadouro. Os totais para os criadouros denominados tanques, poços e cisternas e caixas d'água foram agrupados em uma única variável, chamada criadouros grandes, pois são reservatórios que comportam maior quantidade de água. Os totais para os criadouros denominados depósitos artificiais, pneus, depósitos de barro e outros depósitos também foram agrupados em uma variável designada como criadouros pequenos, pois foram considerados como reservatórios que comportam pouca quantidade de água. Os criadouros barris, tonéis e tinas foram considerados como reservatórios que comportam quantidade intermediária de água, ou seja, criadouros médios.
As variáveis relacionadas aos criadouros árvores e plantas e calhas não puderam ser consideradas na análise devido ao seu reduzido número e a ausência de criadouros positivos, dentre os poucos pesquisados.

A partir da proporção de criadouros positivos para $A$. aegypti, isto é, o número de criadouros positivos de cada tipo dividido pelo total de criadouros inspecionados do mesmo tipo e multiplicado por mil, criaram-se os seguintes indicadores: proporção de criadouros pequenos positivos; proporção de criadouros médios positivos; proporção de criadouros grandes positivos. Criou-se também a variável dicotômica estação, definida como verão, que engloba os meses de outubro a março, e inverno, de abril a setembro.

$\mathrm{Na}$ análise de dados foi utilizada a técnica estatística de análise fatorial por componentes principais com rotação varimax, através do programa estatístico SPSS for Windows versão 6.1.2. Esta análise é um procedimento estatístico redutor do espaço multivariado e foi utilizada com o objetivo de estabelecer fatores associados à ocorrência ou não de formas imaturas de A. aegypti.

Utilizando-se de variáveis meteorológicas e de uma nova variável, que representa o somatório de todos os encontros de fases imaturas de $A$. aegypti em todos os tipos de criadouros, foram elaborados gráficos das variações dessas variáveis durante o período de estudo.

\section{RESULTADOS}

As freqüências relativas, segundo os tipos de criadouros inspecionados (Tabela 1), evidenciaram que $58,04 \%$ e $27,19 \%$ referem-se a depósitos artificiais, tais como suportes para vasos com plantas, vasilhames de plástico, vidro ou louça abandonados no peridomicílio, e outros depósitos, ralos e escoadouros de água, respectivamente. Os tipos de criadouros com maiores percentuais de positividade para formas imaturas de $A$. aegypti foram pneus $(1,41 \%)$, tanques, poços e cisternas $(0,93 \%)$, e barris, tonéis e tinas $(0,64 \%)$. Do total de todos os criadouros inspecionados verificou-se que apenas $0,157 \%$ estava positivo.

Tabela 1 - Criadouros inspecionados, positivos para formas imaturas (larvas e pupas) de Aedes aegypti. Bairro do Galeão, Ilha do Governador, Rio de Janeiro (junho de 1992 a julho de 1994).

\begin{tabular}{lccrc}
\hline Criadouros & Criadouros inspecionados & Freqüência relativa de criadouros & \multicolumn{2}{c}{ Criadouros positivos } \\
& $\mathrm{n}^{\circ}$ & $\%$ & $\mathrm{n}^{\circ}$ & \multicolumn{1}{c}{$\%$} \\
\hline Árvores e plantas & 63.988 & 9,17 & 6 & 0,01 \\
Barris, tonéis e tinas & 7.847 & 1,12 & 50 & 0,64 \\
Calhas & 1.116 & 0,16 & 0 & 0,00 \\
Caixas d'água & 9.701 & 1,40 & 38 & 0,39 \\
Depósitos artificiais & 405.146 & 58,04 & 797 & 0,20 \\
Depósitos de barro & 6.585 & 0,94 & 9 & 0,14 \\
Pneus & 7.289 & 1,04 & 103 & 1,41 \\
Tanques, poços e cisternas & 6.586 & 0,94 & 61 & 0,93 \\
Outros depósitos & 189.811 & 27,19 & 32 & 0,02 \\
\hline Total & 698.069 & 100,00 & 1.096 & 6,37
\end{tabular}


As proporções de criadouros positivos pelas duas estações (Figura 1) mostraram maiores valores, no verão, para os criadouros pequenos e grandes, enquanto no inverno verificou-se maior valor para os criadouros médios.
Ao calcular as médias do total de larvicida utilizado em cada ciclo, observou-se uma redução de inseticida utilizado do $1^{\circ}$ ciclo, $101,036 \mathrm{~kg}$, para o $2^{\circ}$ ciclo, 93,778kg. Deste último para o $3^{\circ}$ ciclo houve novo aumento. Porém, observou-se nova

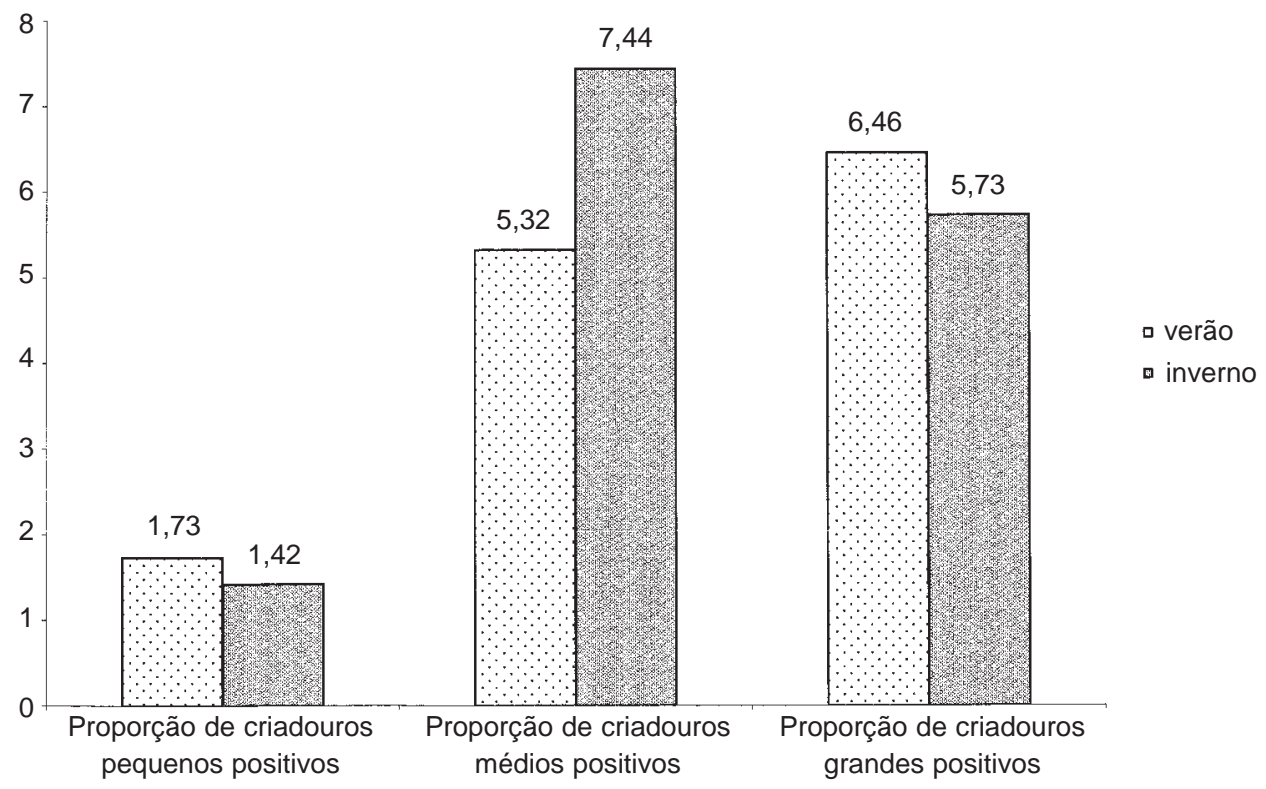

Figura 1- Proporcões de criadouros positivos para formas imaturas de Aedes aegypti pelas estacões verão e inverno. Bairro do Galeão, llha do Governador, Rio de Janeiro (junho de 1992 a julho de 1994).

redução do $3^{\circ}$ para o $5^{\circ}$ ciclo, de $100,469 \mathrm{~kg}$ para $71,562 \mathrm{~kg}$. No $4^{\circ}$ ciclo a média foi de $96,500 \mathrm{~kg}$ e no 6 ciclo, que teve suas atividades até julho de 1994 , foi de $50,058 \mathrm{~kg}$. Também foi possível observar maiores médias para utilização de larvicida nos ciclos 1,3 e 4, correpondentes ao inverno.

Através das proporções de criadouros positivos para os ciclos (Tabela 2), verificou-se que no ciclo 5 correspondente ao verão, todos os indicadores apresentaram altos valores. Contudo, praticamente todas as menores proporções foram observadas no ciclo 2 , também correspondente ao verão. Constatou-se também que a proporção de pneus positivos permaneceu relativamente alta em quatro ciclos, independente da estação. As proporções, segundo o tamanho dos criadouros, mostraram que os criadouros médios tiveram maior valor no ciclo 6 , correspondente ao inverno. Já os grandes criadouros tiveram maior valor no ciclo 5 , correspondente ao verão.

$\mathrm{Na}$ análise da Figura 2 identificamos os períodos de julho e setembro de 1992, maio e dezembro de 1993 e janeiro, abril, maio e junho de 1994, como aqueles com número de criadouros positivos elevados, ou seja, acima de 40. Observou-se também que estes ocorreram nos mesmos meses, ou logo depois daqueles com maiores índices de umidade relativa do ar. Com base na variação da temperatura, máxima e mínima, verificaram-se três períodos com maiores índices: janeiro a fevereiro de 1993, novembro de 1993 e fevereiro de 1994. Durante o período de estudo, os meses que tiveram maiores números de criadouros positivos foram dezembro de 1993 (71) e janeiro de 1994 (307). Observou-se que estes coincidiram com o período de elevados índices de temperatura, e que ocorreram após três meses de intervalo 
entre os ciclos 4 e 5 . Fato semelhante ocorreu em abril e maio de 1994, logo após dois meses sem atividade de campo da FNS e após alto índice de umidade relativa do ar.

\begin{tabular}{|c|c|c|c|c|c|c|}
\hline Estação & $\begin{array}{c}\text { ciclo } 1 \\
\text { Inverno }\end{array}$ & $\begin{array}{l}\text { ciclo } 2 \\
\text { Verão }\end{array}$ & $\begin{array}{l}\text { ciclo } 3 \\
\text { Inverno }\end{array}$ & $\begin{array}{c}\text { ciclo } 4 \\
\text { Inverno }\end{array}$ & $\begin{array}{l}\text { ciclo } 5 \\
\text { Verão }\end{array}$ & $\begin{array}{l}\text { ciclo } 6 \\
\text { Inverno }\end{array}$ \\
\hline Criadouros pequenos & 1,51 & 0,31 & 1,19 & 0,37 & 7,07 & 2,11 \\
\hline depósitos artificiais & 1,60 & 0,39 & 1,43 & 0,47 & 9,78 & 2,77 \\
\hline depósitos de barro & 0,00 & 0,00 & 0,51 & 0,00 & 11,04 & 1,88 \\
\hline pneus & 31,16 & 3,30 & 16,44 & 2,36 & 15,74 & 16,08 \\
\hline outros depósitos & 0,17 & 0,23 & 0,14 & 0,11 & 0,61 & 0,23 \\
\hline Criadouros médios & 8,80 & 3,86 & 6,30 & 0,00 & 8,08 & 14,34 \\
\hline barris e tonéis & 8,80 & 3,86 & 6,30 & 0,00 & 8,08 & 14,34 \\
\hline Criadouros grandes & 5,48 & 1,98 & 4,93 & 1,85 & 18,69 & 8,30 \\
\hline caixas d'água & 5,36 & 1,29 & 3,38 & 1,11 & 10,70 & 1,39 \\
\hline tanques, poços e cisternas & 5,72 & 2,91 & 7,23 & 2,77 & 31,25 & 16,45 \\
\hline
\end{tabular}

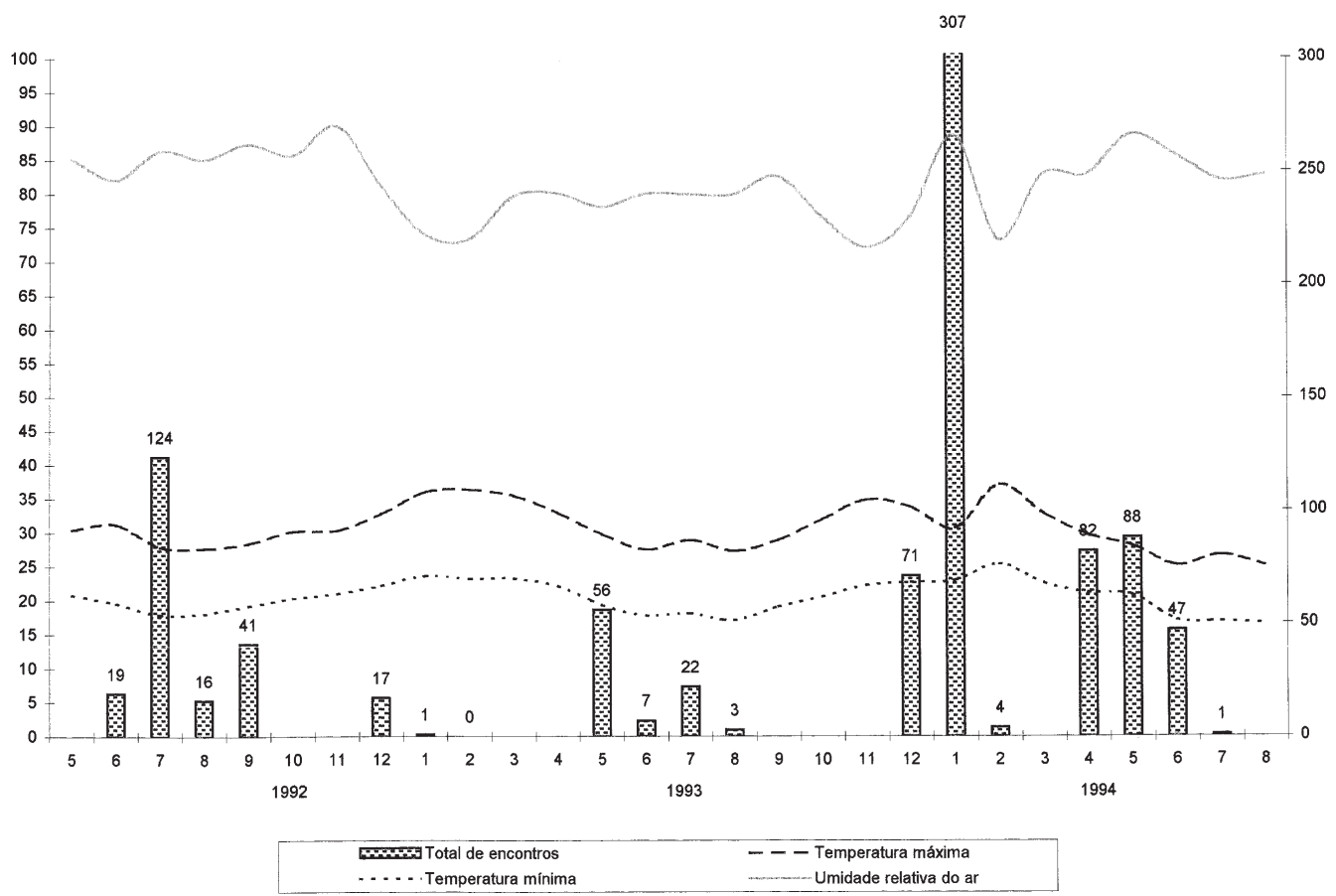

Figura 2- Variacão mensal de temperatura (máxima e mínima), umidade relativa do ar e do total de criadouros positivos para formas imaturas de Aedes aegypti. Bairro do Galeão, Ilha do Governador, Rio de Janeiro (junho de 1992 a julho de 1994).

Análise fatorial. Utilizando-se a técnica de análise fatorial por componentes principais, somente para a estação verão, foram extraídos três fatores que explicaram $69,1 \%$ da variância total. Para a estação inverno também foram extraídos três fatores que explicaram $50,8 \%$ da variância total. Os resultados obtidos foram os seguintes: 
Verão. Observando os valores encontrados no Fator 1, que explicou $27,4 \%$ da variância (Tabela $3)$, verificou-se que as seguintes variáveis apresentaram grande representatividade neste eixo: média da pressão atmosférica, temperatura máxima, temperatura mínima e umidade relativa do ar. De acordo com os sinais das cargas foram encontradas correlações positivas nas variáveis temperatura máxima e temperatura mínima. Assim, este fator foi denominado indicador meteorológico.

O Fator 2, denominado uso de larvicida e controle de criadouros, explicou $22,2 \%$ da variância total. As variáveis que apresentaram maior representatividade foram: quantidade de larvicida utilizado; criadouros pequenos eliminados, criadouros médios eliminados e criadouros grandes eliminados (Tabela 3). Os sinais das cargas mostraram correlações positivas em todas as variáveis.

Para o Fator 3 , que explicou $19,5 \%$ da variância total, observaram-se as seguintes variáveis com grande valor representativo (Tabela 3): proporção de criadouros pequenos positivos e proporção de criadouros grandes positivos. Os sinais das cargas das duas

Tabela 3 - Análise fatorial de variáveis associadas à ocorrência de fases imaturas de Aedes aegypti, para a estação verão. Ilha do Governador, Rio de Janeiro, 1992-1994.

\begin{tabular}{|c|c|c|c|}
\hline Variáveis & Fator 1 & Fator 2 & Fator 3 \\
\hline Quantidade de larvicida utilizado &,- 36556 & ,65357 & ,02102 \\
\hline Criadouros pequenos eliminados &,- 13617 & ,81856 & ,17899 \\
\hline Criadouros médios eliminados & , 19719 & ,75125 &,- 04800 \\
\hline Criadouros grandes eliminados & ,12930 & ,75331 &,- 18486 \\
\hline Proporção de criadouros pequenos positivos para $A$. aegypti & ,03931 &,- 04935 & ,94722 \\
\hline Proporção de criadouros médios positivos para $A$. aegypti & ,22665 & ,37538 & ,19944 \\
\hline Proporção de criadouros grandes positivos para $A$. aegypti &,- 02314 &, 08440 & ,92219 \\
\hline Média da pressão atmosférica &,- 61303 &,- 15711 &,- 28923 \\
\hline Temperatura máxima & ,93769 & ,03508 &,- 17466 \\
\hline Temperatura mìnima & ,86840 &,- 10575 & ,29758 \\
\hline Umidade relativa do ar &,- 86177 &,- 04712 & ,33539 \\
\hline
\end{tabular}

variáveis mostraram correlações positivas. Este fator foi denominado indicador de positividade para grandes e pequenos criadouros.

- Inverno. As cargas encontradas para o Fator 1, que explicou $34,2 \%$ da variância total, mostraram que as variáveis que tiveram maior representatividade foram: criadouros grandes eliminados, média da pressão atmosférica, temperatura máxima, temperatura mínima, e umidade relativa do ar (Tabela 4). De acordo

Tabela 4 - Análise fatorial de variáveis associadas à ocorrência de fases imaturas de Aedes aegypti, para a estação inverno. Ilha do Governador, Rio de Janeiro, 1992-1994.

\begin{tabular}{lccc}
\hline Variáveis & Fator 1 & Fator 2 & Fator 3 \\
\hline Quantidade de larvicida utilizado &, 38643 &, 76734 &,- 04217 \\
Criadouros pequenos eliminados &, 09756 &, 92593 &,- 01775 \\
Criadouros médios eliminados &, 11599 &,, 82681 &, 02638 \\
Criadouros grandes eliminados &, 61793 &, 13501 &,- 03422 \\
Proporção de criadouros pequenos positivos para A. aegypti &, 15757 &,- 02911 &, 77608 \\
Proporção de criadouros médios positivos para A. aegypti &,- 09915 &, 08848 &, 68544 \\
Proporção de criadouros grandes positivos para A. aegypti &,- 03932 &,- 07913 &, 79903 \\
Média da pressão atmosférica &,- 84799 &,- 16397 &, 07598 \\
Temperatura máxima &, 88694 &, 22587 &,- 12405 \\
Temperatura ml̀nima &, 77248 &, 33656 \\
Umidade relativa do ar &,- 58870 &, 08580 &, 06511 \\
\end{tabular}


com os sinais das cargas, foram encontradas correlações negativas para a média da pressão atmosférica e para umidade relativa do ar. Este fator foi denominado indicador meteorológico e de controle de grandes criadouros.

No Fator 2, denominado indicador de uso de larvicida e controle de pequenos e médios criadouros, que explicou $19,3 \%$ da variância total, observamos que as variáveis quantidade de larvicida utilizado, criadouros pequenos eliminados e criadouros médios eliminados tiveram maior representatividade (Tabela 4).
De acordo com os sinais das cargas, foram encontradas correlações positivas.

Para o Fator 3, que explicou $14,2 \%$ da variância total, as variáveis que apresentaram maior representatividade foram: proporção de criadouros pequenos positivos, proporção de criadouros médios positivos, proporção de criadouros grandes positivos e umidade relativa do ar (Tabela 4). Todas essas apresentaram correlação positiva. Assim, este fator foi denominado indicador da proporção de criadouros positivos e de umidade relativa do ar.

\section{DISCUSSÃO}

Uma das características que distingue A. aegypti de outras espécies de mosquitos é a capacidade de desenvolver suas larvas em grande variedade de ambientes naturais e artificiais5 310 11. Segundo Fochs et al5, certos tipos de reservatórios podem proporcionar um maior desenvolvimento de fases imaturas do que outros. Em New Orleans, nos EUA, pneus compreenderam apenas $6 \%$ do total dos reservatórios inspecionados, contudo possuiam $25,7 \%$ do total das formas imaturas 5 . No Brasil, os resultados do estudo desenvolvido por Lopes et al9 em Londrina, Paraná, mostraram que, do total de 1.600 pneus inspecionados, 24,7\% continham larvas de culicídeos. Sendo que, em 134 reservatórios de água inspecionados, foram identificados $24,6 \%$ que estavam positivos para larvas de $A$. aegypti.

Nesse trabalho, $58,04 \%$ do total de criadouros inspecionados foram constituídos por suportes para vasos com plantas, vasilhames de plástico, vidro ou louça abandonados no peridomicílio. Contudo, os maiores percentuais de criadouros positivos foram observados para pneus $(1,41 \%)$, tanques, poços e cisternas $(0,93 \%)$, e barris, tonéis e tinas $(0,64 \%)$. Ao compararmos as proporções de criadouros positivos pelas estações verão e inverno (Figura 1), verificamos que aqueles que apresentaram maiores valores durante o verão foram os grandes criadouros destinados ao armazenamento de água, ou seja, tanques, poços, cisternas e caixas d'água, e os criadouros provenientes do lixo doméstico, pneus, depósitos artificiais, depósitos de barro e outros depósitos. Já no inverno, verificamos maior valor para aqueles utilizados como pequenos reservatórios de água, que englobam barris, tonéis, tinas.

O número de criadouros existentes não interfere diretamente na manutenção do número de formas imaturas de $A$. aegypti. As características de cada um destes, bem como a forma como são tratados, devem ser levadas em consideração. Os recipientes provenientes do lixo doméstico normalmente possuem menor tamanho, possibilitando, por um lado, rápido acúmulo de água de chuva e por outro, rápida evaporação de água acumulada. Nos meses de verão, que normalmente possuem altas temperaturas e alto índice pluviométrico, estes são rapidamente e freqüentemente preenchidos com água das chuvas, tornando-se, assim, ótimos criadouros potenciais, pois as larvas podem desenvolver-se em um período menor de tempo, desde que haja alimento suficiente. Já nos meses de inverno, que normalmente apresentam menor temperatura e menor pluviosidade, as larvas necessitam de um período mais prolongado para seu desenvolvimento. Como a reposição de água pelas chuvas é menos freqüente nesta época, os recipientes tornam-se criadouros menos eficientes. Quanto a tanques, poços e cisternas, estes são, possivelmente, mais utilizados pela população nos meses de verão, quando o fornecimento de água encanada permanece contínuo. Durante os meses de inverno, normalmente com menor índice pluviométrico, estes recipientes podem ser desativados, sendo utilizados em seu lugar recipientes menores e de fácil manipulação, tais como barris, tonéis e tinas, conforme citado por Valla e col25. Desse modo, os grandes reservatórios de água tornamse criadouros potenciais principalmente durante a estação das chuvas. No caso de barris, tonéis e tinas, pode-se dizer que há uma freqüente retirada da tampa, caso exista, tanto para retirada como para reposição de água, o que pode proporcionar a entrada de fêmeas de Aedes para postura. Desse modo, existe a manutenção da quantidade de água suficiente para permanência 
do vetor, independente da estação. Quanto às caixas d'água, mesmo que existam tampas, em muitas regiões a pressão da água nos canos não é suficiente para enchê-las, o que faz com que muitas sejam preenchidas de outras formas, acarretando sua abertura freqüente e tornando possível a entrada de fêmeas de Aedes, também independente da estação. Já os pneus, que devido a sua forma proporciona baixa evaporação de água do interior 4 , são ótimos criadouros porque, mesmo nos períodos com baixa pluviosidade, a água acumulada permanece em seu interior por um maior período.

Como foi citado anteriormente, as características dos diferentes tipos de criadouros e suas formas, devem ser consideradas no momento do estudo e no direcionamento das atividades de controle e tratamento com uso de larvicida.

De acordo com o presente estudo, o ciclo 5, no qual foram observadas maiores proporções de criadouros positivos, teve seu início após três meses sem atividades da FNS. O mesmo ocorreu nos meses de verão, quando foi verificado maior índice de umidade relativa do ar. Observou-se também que neste mesmo ciclo houve uma redução na média da quantidade de larvicida utilizado. Quanto as menores proporções de criadouros positivos, verificou-se que ocorreram principalmente no ciclo 2 , desenvolvido também em meses de verão. Todavia, sem haver interrupção de três meses de atividade da FNS, antes de seu início e com média de $93.778 \mathrm{~kg}$ de larvicida utilizado, em contraste com a média de $71.562 \mathrm{~kg}$ de larvicida utilizado no ciclo 5 . Tais fatos apontam para a necessidade de controle contínuo durante todo o ano. Além disso, não deve ser descartada a importância da participação popular no controle do vetor11 121724 .

Em vários países de clima tropical, tem sido demonstrada associação entre pluviosidade, densidade larval e incidência de dengue 8 . Ainda que não tenhamos os índices pluviométricos do período para a llha do Governador, e os números de casos de dengue notificados sejam relativamente pequenos, os resultados desse estudo indicam relação semelhante entre os fatores meteorológicos e número de encontro de larvas. Nos meses em que foram verificados maiores índices de umidade relativa do ar, ou logo após estes, foram notadas as maiores médias de número de criadouros positivos. Como a temperatura máxima e mínima teve suas médias, para todo o período de estudo, em $30,41^{\circ} \mathrm{C}$ e $20,37^{\circ} \mathrm{C}$, respectivamente, acreditase que apenas os extremos tenham efeito diferenciado sob a população de larvas. Contudo, deve ser levado em consideração que $A$. aegypti pode reproduzir-se dentro das residências, e que, mesmo nos períodos com baixas temperaturas externas e em períodos com menor pluviosidade, podemos encontrar no intradomicílio um ambiente propício para o desenvolvimento de larvas de Aedes6.

Análise fatorial. A análise fatorial para os meses de verão mostrou que o principal fator determinante da ocorrência de fases imaturas de $A$. aegypti é aquele que leva em consideração os fatores meteorológicos. Com menor participação verificamos o indicador de uso de larvicida e controle de criadouros e, por último, o indicador de positividade para grandes e pequenos criadouros. Logo, a ocorrência de larvas e pupas, nesta estação, está associada principalmente aos fatores meteorológicos. A eliminação e tratamento de criadouros pelos agentes da FNS apresentaram-se como menos importantes e, vale ressaltar, a variável utilização de larvicida teve a menor representatividade nesse fator. No terceiro fator, indicador de positividade para grandes e pequenos criadouros, a variável proporção de criadouros médios não foi representativa, provavelmente devido à menor utilização de pequenos reservatórios de água para uso doméstico nesta estação.

Ao observarmos os resultados para a estação inverno, constatou-se que o fator que teve maior participação na ocorrência de fases imaturas de A. aegypti foi também o indicador meteorológico e de controle de grandes criadouros, seguido pelo uso de larvicida e controle de pequenos e médios criadouros e com menor participação o indicador da proporção de criadouros positivos e de umidade relativa do ar. As variações mais acentuadas na ocorrência de formas imaturas durante o inverno estão principalmente relacionadas às variações meteorológicas e à ação dos agentes da FNS no controle de grandes criadouros utilizados para o armazenamento de água para uso doméstico. De forma semelhante aos resultados para o verão, a utilização de larvicida e a eliminação de criadouros provenientes de lixo doméstico e de pequenos reservatórios de água, atribuídas aos agentes da FNS, apresentaram menor participação na ocorrência das formas imaturas do vetor. Além disso, a proporção de criadouros médios positivos mostrou-se representativa no terceiro fator, assim 
como as proporções de criadouros grandes e pequenos.

Estes achados corroboram os resultados das proporções de criadouros positivos segundo as estações, sugerindo uma menor atenção por parte dos agentes da FNS durante o inverno em relação aos pequenos reservatórios de água para uso doméstico, o que favorece a manutenção de formas imaturas de $A$. aegypti neste período. No que diz respeito aos vetores, as medidas de controle preconizadas pelo Programa Nacional de Controle de Dengue buscam reduzir ao máximo a densidade de infestação pelo $A$. aegypti. Esta redução dar-se-ia através da inativação de criadouros do vetor e aplicação de larvicida nos período interepidêmicos. Nos períodos epidêmicos, associa-se ao método focal a aplicação espacial de inseticida para redução da forma adulta do mosquito15. Contudo, este estudo, indica que, devido à interrupção das atividades em campo da FNS, houve rápido aumento no número de criadouros positivos nos meses de dezembro de 1993 e janeiro de 1994. Segundo Mitchell13, quando se verifica um relaxamento nas atividades de controle de A. aegypti, sua população rapidamente retorna aos níveis anteriores. Além disso, a ação da FNS durante o inverno, considerado como interepidêmico, não demonstrou grande participação no controle de formas imaturas deste vetor, como pode ser verificado através das proporções de criadouros positivos.

\section{AGRADECIMENTOS}

O autor agradece ao Serviço Regional de Proteção ao Vôo do Rio de Janeiro pelo fornecimento dos dados meteorológicos, à Coordenadoria Regional da Fundação Nacional de Saúde no Rio de Janeiro, pelo acesso às informações referentes ao vetor, e aos pesquisadores da Fundação Oswaldo Cruz, Ricardo Santos, Carlos E. A. Coimbra Jr., Marília de Sá Carvalho e Ricardo Lourenço de Oliveira, pelo auxílio na análise e interpretação dos dados, e pela leitura crítica dos originais.

\section{REFERÊNCIAS BIBLIOGRÁFICAS}

1. Barrera R, Avila J, Gonzalez-Tellez S. Unreliable supply of potable water and elevated Aedes aegypti larval indices: a causal relationship? Journal of the American Mosquito Control Association 9:189-195, 1993.

2. Consoli RAGB, Lourenço-de-Oliveira R. Principais mosquitos de importância sanitária no Brasil. Editora Fiocruz, Rio de Janeiro, RJ, 1994.

3. Focks DA, Haile DG, Daniels E, Mount GA. Dynamic life table model for Aedes aegypti (Diptera: Culicidae): analysis of the literature and model development. Journal of Medical Entomology 30:1003-1017, 1993.

4. Focks DA, Haile DG, Daniels E, Mount GA. Dynamic life table model for Aedes aegypti (Diptera: Culicidae): Simulation results and validation. Journal of Medical Entomology 30:1018-1028, 1993.

5. Focks DA, Sackett SR, Bailey DL, Dame DA. Observations on container-breeding mosquitoes in New Orleans, Louisiana, with an estimate of the population density of Aedes aegypti (L.). American Journal of Tropical Medicine and Hygiene 30:1329-1335, 1981.

6. Herrera-Bastos E, Prevots DR, Zarate ML, SepulvedaAmor J. First reported outbreak of classical dengue fever at 1,700 meters above sea level in Gerrero State, Mexico, June 1988. American Journal of Tropical Medicine and Hygiene 46:649-653, 1992.

7. Instituto de Planejamento do Município do Rio de Janeiro. Anuário estatístico da cidade do Rio de Janeiro 93/94. Iplanrio, Rio de Janeiro, RJ, 1995.
8. Kuno G. Review of the factors modulating dengue transmission. Epidemiologic Reviews 17:321-335, 1995.

9. Lopes J, Silva MAN, Borsato AM, Oliveira VDRB, Oliveira FJA. Aedes (Stegomyia) aegypti L. and associated culicidae fauna in an urban area of southern, Brazil. Revista de Saúde Pública 27:326-333, 1993.

10. Macoris MLG, Mazine CAB, Andrighetti MTM, Ysamuro S, Silva ME, Nelson MJ, Winch PJ. Factors favoring houseplant container infestation with Aedes aegypti larvae in Marília, São Paulo, SP, Brazil. Revista Panamericana de Salud Pública 1:280-286, 1997.

11. Chiaravalloti-Neto F. Conhecimentos da população sobre dengue, seus vetores e medidas de controle em São José do Rio Preto, São Paulo. Cadernos de Saúde Pública 13:447-453, 1997.

12. Marzochi KBF. Dengue in Brazil - situation, transmition and control. A proposal for ecological control. Memórias do Instituto Oswaldo Cruz 89:235-245, 1994.

13. Mitchell CJ. Environmental management for vector control. In: Beaty BJ, Marquardt WC (eds) The biology of disease vectors, University Press of Colorado, Niwot, $p$. 492-501, 1996.

14. Nathan MB, Knudsen AB. Aedes aegypti infestation characteristics in several Caribbean countries and implications for integrated community-based control. Journal of the American Mosquito Control Association 7:400-404, 1991. 
15. Nobre A, Antezana D, Tauil PL. Febre amarela e dengue no Brasil: Epidemiologia e controle. Revista da Sociedade Brasileira de Medicina Tropical 27(supl. 3):59-66, 1994.

16. Reiter P, Amador MA, Anderson RA, Clark GG. Short report: dispersal of Aedes aegypti in an urban area after blood feeding as demonstrated by rubidium-marked eggs. American Journal of Tropical Medicine and Hygiene 52:177-179, 1995.

17. Schultz GW. Seasonal abundance of dengue vectors in Manila, Republic of the Philippines. Southeast Asian Journal of Tropical Medicine and Public Health 24:369375, 1993.

18. Service MW. Importance of ecology in Aedes aegypti control. Southeast Asian Journal of Tropical Medicine and Public Health 23:681-690, 1992.

19. Silveira AC. Situação epidemiológica do dengue e febre amarela no Brasil e nas Américas. Apresentado na mesa redonda para elaboração do Plano Diretor de Erradicação do Aedes aegypti no Brasil. Ministério da Saúde, Brasília, DF, 1995.

20. Sousa LC, Ribeiro ZM, Moreira WLC, Araújo JMP, Teixeira AR, Braga PH, Lima JWO. Infestação de criadouros naturais por Aedes aegypti (Linnaeus) (Diptera: Culicidae) em um cemitério de Fortaleza. Revista da Sociedade Brasileira de Medicina Tropical 31(supl. 1):447, 1998.

21. Tauil PL. Dengue e febre amarela: epidemiologia e controle no Brasil. Revista da Sociedade Brasileira de Medicina Tropical 20(supl. 1):150-151, 1987.

22. Tun-Lin W, Kay BH, Barnes A. The premise condition index: a tool for streamlining surveys of Aedes aegypti. American Journal of Tropical Medicine and Hygiene 53:591-594, 1995.

23. Tun-Lin W, Kay BH, Barnes A. Understanding productivity, a key to Aedes aegypti surveillance. American Journal of Tropical Medicine and Hygiene 53:595-601, 1995.

24. Valla VV. Educação, saúde e cidadania: Investigação científica e assessoria popular. Cadernos de Saúde Pública 8:30-40, 1992.

25. Valla, VV, Oliveira RM. Conhecendo a Região da Leopoldina. Escola Nacional de Saúde Pública/Fiocruz, Rio de Janeiro, RJ, 1995. 